\title{
An Insight into Impact of Partial Ground and Dual Trapezoidal Slots on Bandwidth and Gain considerations for a Microstrip Antenna Array for WiMax Application
}

\author{
G. Viswanadh Raviteja ${ }^{1}$ \\ ${ }^{1}$ Department of Electronics \& Communication Engineering, ANITS, Visakhapatnam, India \\ *corresponding author, E-mail: tejar512@gmail.com
}

\begin{abstract}
In this work, design and analysis of microstrip patch antenna is carried out. A $(2 X 1)$ antenna array is considered, with dimensions (W x L) as $35.11 \mathrm{~mm} \times 27.13$ $\mathrm{mm}$. The dielectric substrate is taken to be FR4 epoxy with dielectric constant as 4.3 and loss tangent of 0.02 . Dual trapezoidal slots are introduced to improve the gain considerations for the considered antenna array. The simulations are carried out and it is observed that the gain is improved. As a second stage in the work, to improve the bandwidth of operation for the dual trapezoidal antenna array, the concept of partial ground is taken into consideration. The simulations are carried in HFSS. It is found out that the introduction of partial ground improved the bandwidth of the antenna structure considered while preserving the gain to the maximum extent possible. The gain was found to be $7.0875 \mathrm{~dB}$ with centre frequency $2.4020 \mathrm{GHz}$. The frequency range below $-10 \mathrm{~dB}$ for the considered antenna array structure with partial ground was around $2.3 \mathrm{GHz}$ to $2.6 \mathrm{GHz}$. This range is utilized in the WiMax application which covers the frequency ranges $(2.3$ $\mathrm{GHz}$ to $2.4 \mathrm{GHz}$ ) and (2.496 GHz to $2.690 \mathrm{GHz})$.
\end{abstract}

\section{Introduction}

The demand for wireless systems made the industry to make many new antenna structures suitable for working in the range of single band to multiple bands. Mircostrip antennas and printed antennas were two favorites in this area at that time [1]. With the advantage of having extremely low profile, less cost and ease of fabrication, the microstrip patch antennas gained much importance in the wireless industry. Some of the applications are the mobile communications, Radio frequency identification systems, etc. [2]. These antennas are usually of thin scale and are easily compatible in the use of integrated circuits. Because of the vast research carried out in the recent years, several commercial applications of the microstrip patch antennas came into existence. The usual form of a microstrip patch antenna is a patch being placed on a grounded dielectric substrate [3]. Quarter wavelength and half wavelength rectangular patch antennas are most widely used. But later on other configurations such as triangular, circular and ring patches also came into existence [4]. However disadvantages circulated around these antennas. Extremely narrow bandwidth and less gain are some of them. Many researches are being done to improve the gain of the patch antennas [5]. This is implemented using different antenna sizes, shapes, parameters, designs and materials [6-9]. With the advancement of technologies it became necessary to decrease the size of the antenna. Slots are generally preferred when size of the antenna is a constraint. Different shapes of slots were also proposed over the years [10-12]. In particular, the use of dual trapezoidal slots is discussed in [10]. To meet the requirements on the bandwidth constraints, the use of partial ground were introduced [1518].This is done to increase the efficiency levels of the wireless systems.

In this paper, a ( $2 \times 1)$ microstrip patch antenna array is considered. Mirrored trapezoidal slots are cut on the patches to improve the patch antenna characteristics. The antenna is designed and simulated using the HFSS software.

\section{Antenna Design Structure}

In order to overcome the limitations seen in single antenna, antenna arrays are proposed. Antenna arrays are group of similar antennas placed in particular geometry. This is done to enhance the radiation properties to the point of interest. The overall gain is said to be improved. The interference problem can be suppressed to a minimum level. To determine the signal; which is of interest and cancel out all other signals [13]. Therefore antenna arrays provide significant advantages when compared to single antenna structure.

For the proposed antenna, a ground plane of (W x L) $90 \mathrm{~mm}$ and $50 \mathrm{~mm}$ is considered. FR4 epoxy is taken to be the dielectric substrate with permittivity of ' 4.3 ' and loss tangent of ' 0.02 '. The design considerations regarding the length and width of the patch are considered from the general rectangular patch antenna equation for length and width discussed in [14]. Since, the idea is to design an antenna for WiMax application, which covers ranges $(2.3$ $\mathrm{GHz}$ to $2.4 \mathrm{GHz})$ and $(2.496 \mathrm{GHz}$ to $2.690 \mathrm{GHz})$, the width and length are considered by substituting respective values in the empirical formula for rectangular patch antenna given in [14]. Therefore a (2 X 1) patch antenna array is designed with two rectangular microstrip patch antennas, each of dimensions (W x L) $35.11 \mathrm{~mm}$ and $27.13 \mathrm{~mm}$. These dimensions yielded an overall antenna design which would resonate in the WiMax frequency range. The height of the substrate is ' $1.6 \mathrm{~mm}$ '. 


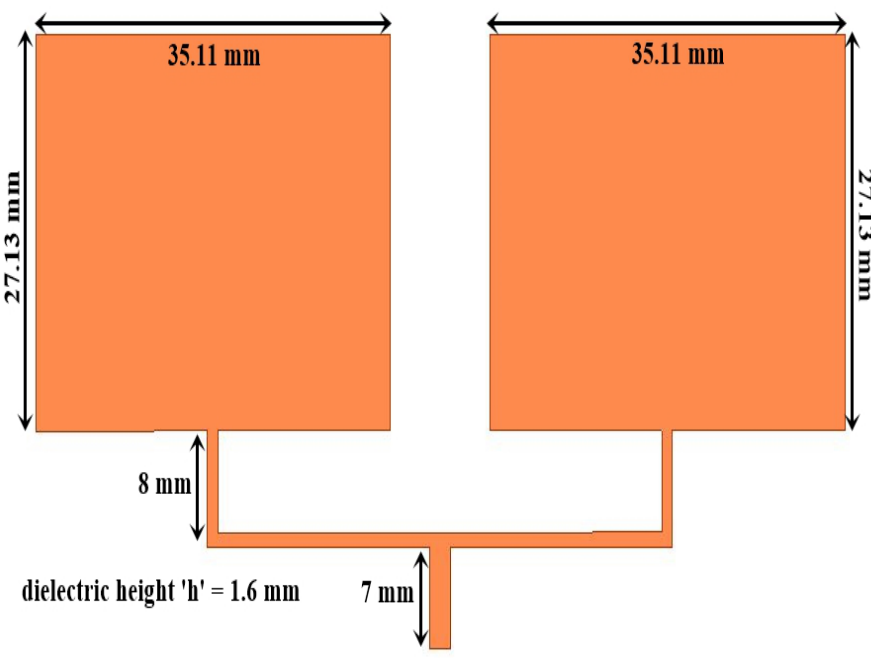

Figure 1 A conventional 2 X 1 microstrip patch antenna structure

When etched in a desired manner, slots are made to be formed on the radiator. Slots which are made on the radiating patch make the excited surface currents to wander, which leads to decrease in the resonant frequency of the antenna. As a result, the antenna is minimized, when it is compared to a patch antenna without slots. Also, introduction of slots made the patch antenna to work in broader frequency ranges [11]. Now, for the two patch antennas, dual trapezoidal slots are cut. In general, a trapezoid has two parallel sides and two non-parallel sides. Among the two parallel sides, one side form the long base and the other side form the short base. The other two nonparallel sides are called as 'legs'. To achieve good impedance matching, the parameters of this trapezoid structure, namely ' $p$ ', 'q', 'r' and 's' are important. Firstly, the ' $q$ ' which forms the short base is considered for an appropriate length, and ' $p$ ' which forms the long base is adjusted for different lengths (starting from $20 \mathrm{~mm}$ and thereby decreasing $1 \mathrm{~mm}$ in length). For each instance after short and long base are fixed, the side legs ' $r$ ' and's' attached which completes the trapezoid structure. The structure is tuned for different ' $p$ ' lengths till proper impedance matching was achieved. Therefore, the optimized values for the long base were ' $20 \mathrm{~mm}$ ' and the short base was found to be ' $7 \mathrm{~mm}$ '. The side legs which form the non-parallel sides are ' $6 \mathrm{~mm}$ ' on both sides. The trapezoidal structure is shown in figure 1.

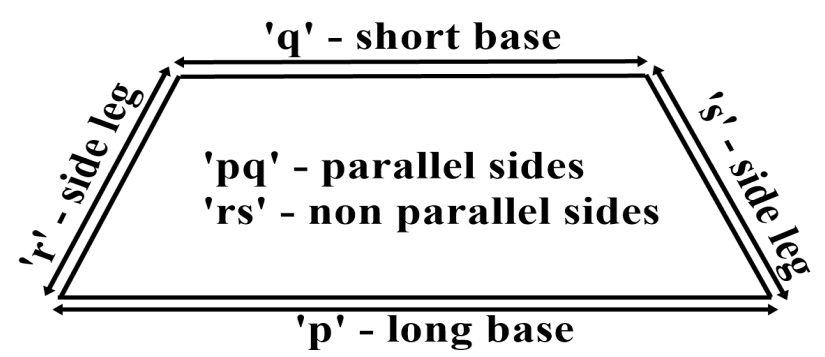

Figure 2 Trapezoid structure

The proposed rectangular microstrip patch antenna with dual trapezoidal slots is shown in the figure 3 .

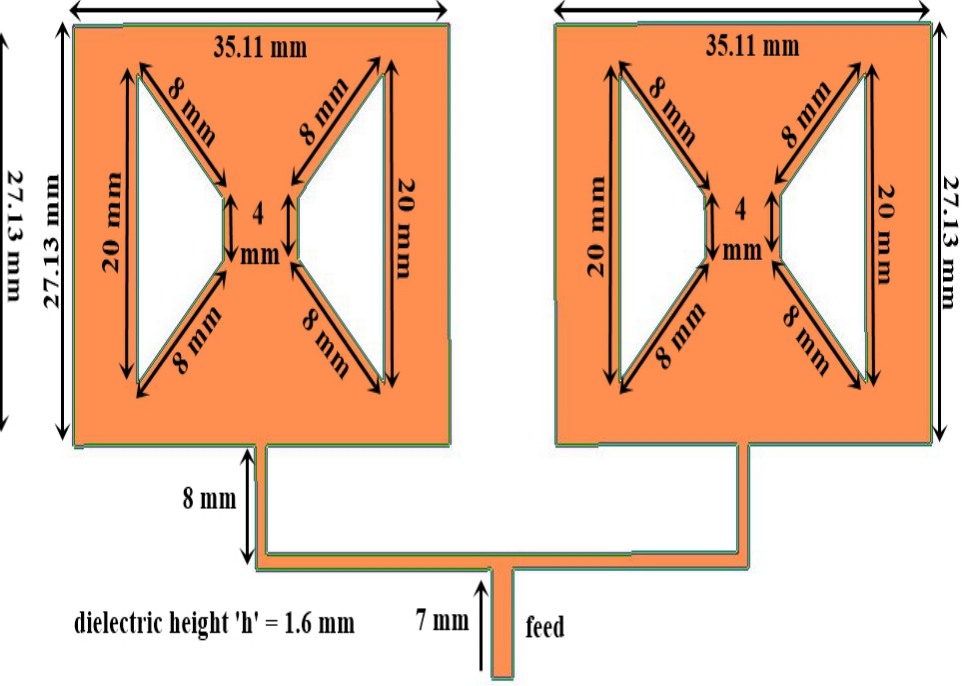

Figure 3 Patch antenna structure with dual trapezoidal slots

Feeding for the proposed antenna is given by a microstrip transmission line having a characteristic impedance of ' 50 $\Omega$ '.

\section{Findings from the Antenna Array And Slotted Antenna Array}

\subsection{For 2 X 1 Patch Antenna Array}

Firstly, the properties of the conventional 2 X 1 patch antenna array are studied. The $2 \mathrm{X} 1$ patch antenna is constructed simulated using the HFSS simulation software. The findings for simulated S11 are plotted as shown in the given figure 4 below.

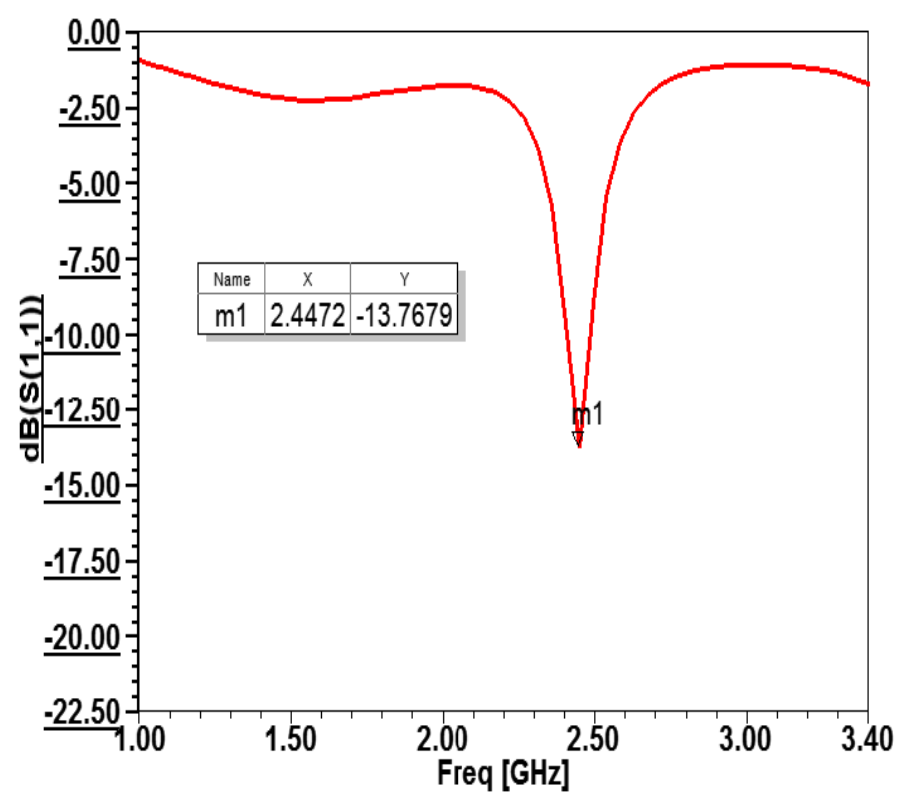

Figure 4 The simulated S11 for the conventional 2 X 1 microstrip antenna

The simulated S11 for the conventional 2 X 1 microstrip antenna showed $-13.7679 \mathrm{~dB}$ for a centre frequency of 2.44 GHz. The bandwidth was found to be " $0.0757 \mathrm{GHz}$ " with the frequency ranges of $2.4065 \mathrm{GHz}$ to $2.4822 \mathrm{GHz}$. 
The VSWR is calculated to be 1.5155 at the frequency of $2.44 \mathrm{GHz}$ and the gain of the antenna array is measured to be $3.8 \mathrm{~dB}$. The reflection coefficient is found out to be 0.20 . It is calculated from the relation between reflection coefficient and VSWR. The reflected power and mismatch loss is calculated to be $4.2 \%$ and $0.19 \mathrm{~dB}$. The VSWR and gain plots are given in the figure 5 and figure 6 below.

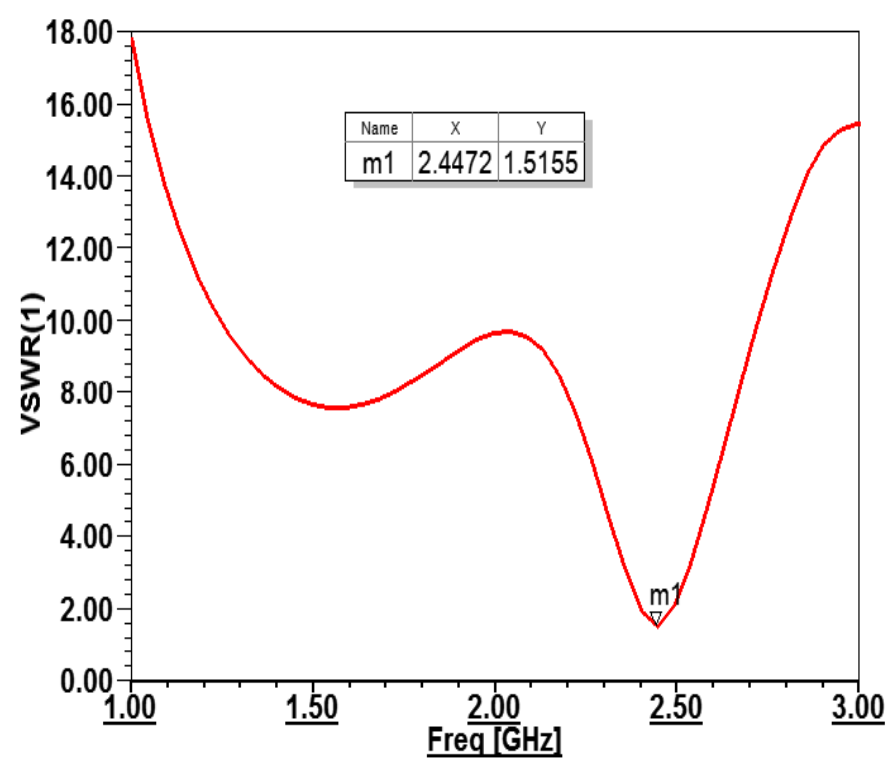

Figure 5 VSWR plot for the conventional 2 X 1 microstrip antenna
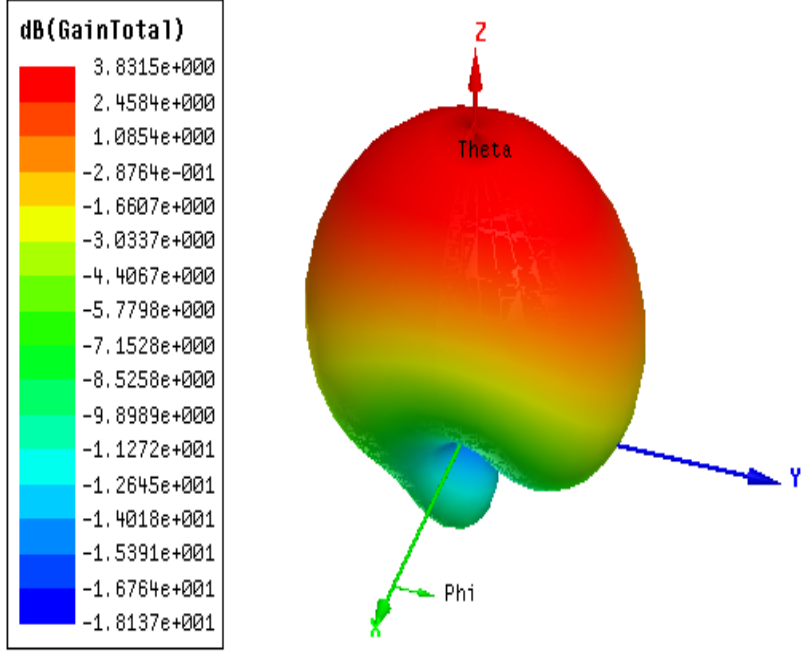

Figure 6 The gain plot for the conventional 2 X 1 microstrip antenna

\subsection{For Dual Trapezoidal Slot Antenna Array}

On the other hand, for the microstrip antenna array with dual trapezoidal slots, the simulated S11 is calculated to be $-28.48 \mathrm{~dB}$ with centre frequency at $2.31 \mathrm{GHz}$. The bandwidth of this antenna array is measured to be 0.1244 $\mathrm{GHz}$ with the frequency ranging from $2.25 \mathrm{GHz}$ to 2.38 $\mathrm{GHz}$. The S11 plot is given in the figure 7 below.

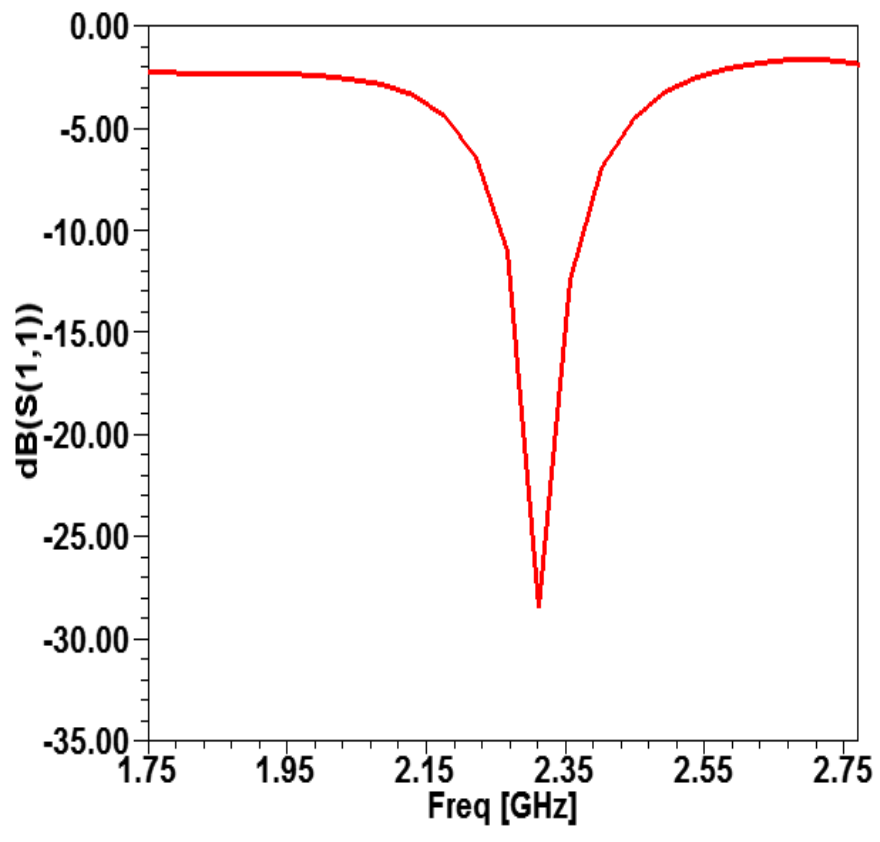

Figure 7 The simulated S11 for the trapezoidal slotted 2 X 1 microstrip antenna

Secondly, the VSWR is found out to be 1.0783 which is less than 2. The gain of the slotted antenna array is calculated and was found out be $7.83 \mathrm{~dB}$. The reflection coefficient is found to be 0.04 in this case. The reflected power is $0.1 \%$ and the mismatch loss is $0.01 \mathrm{~dB}$. Therefore, when compared with the conventional microstrip patch antenna, the reflected power is decreased and the mismatch loss is significantly decreased, leading to better performance of microstrip antenna with slots. The plots for the VSWR and gain are plotted in the figure 8 and figure 9 below.

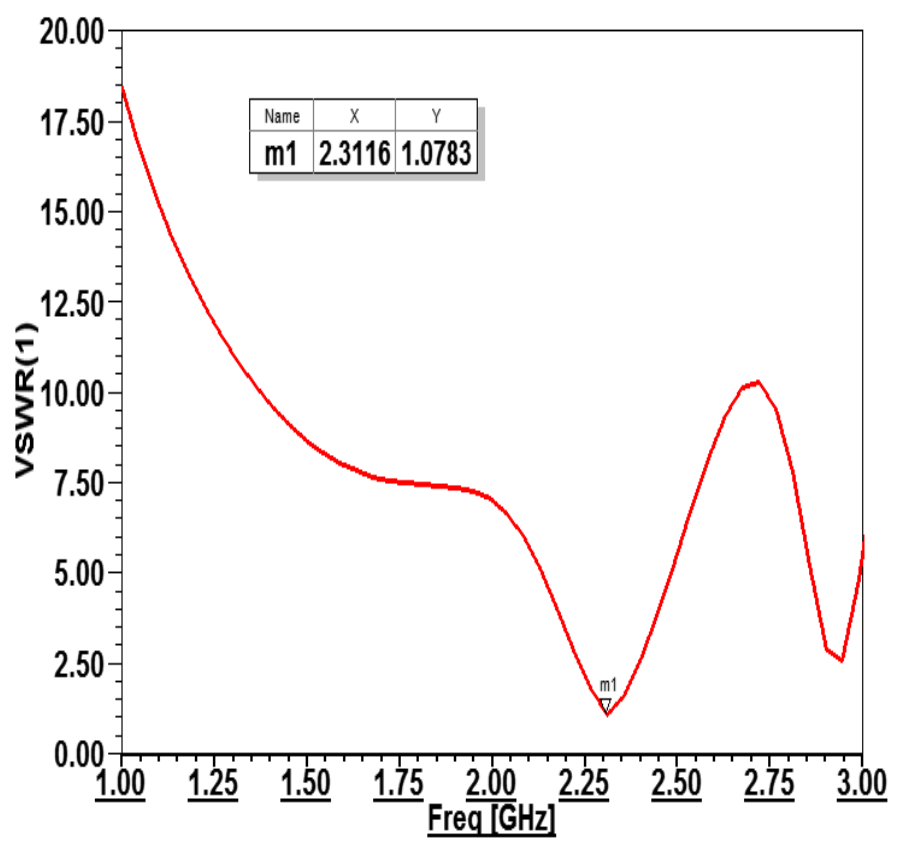

Figure 8 The VSWR plot for the trapezoidal slotted 2 X 1 microstrip antenna 


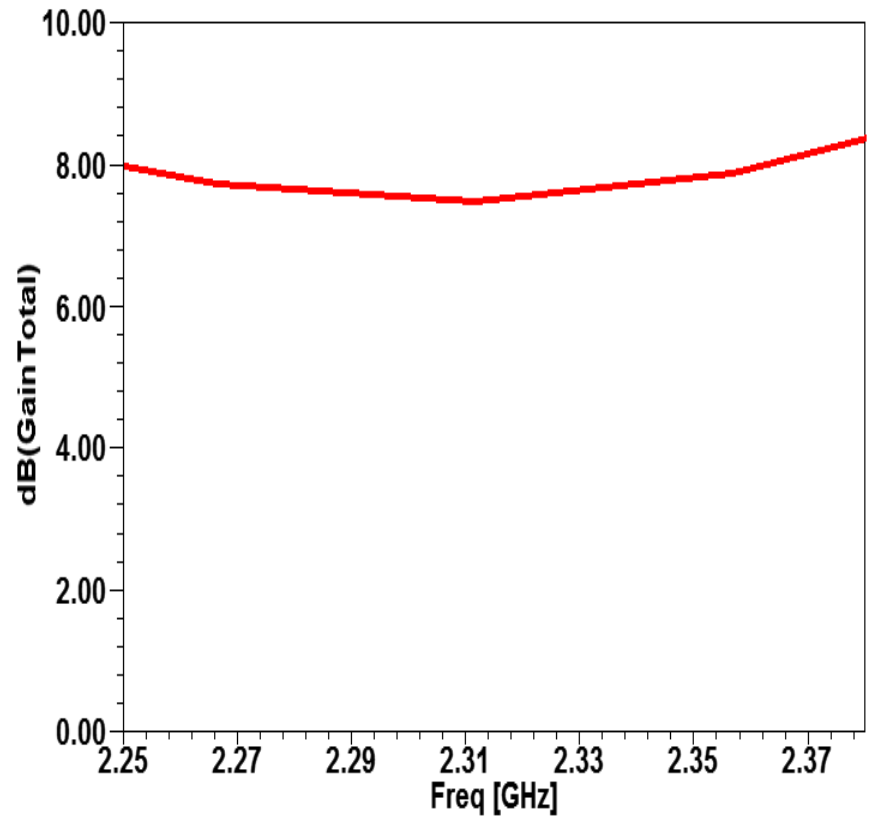

Figure 9 The gain plot for the trapezoidal slotted 2 X 1 microstrip antenna

\section{Dual Trapezoidal Slot Microstrip Antenna Array with Partial Ground}

It is to be noted that even though the gain of the antenna array is significantly improved to $7.83 \mathrm{~dB}$ when dual trapezoidal slots are used when compared to the $3.83 \mathrm{~dB}$ gain of conventional $2 \mathrm{X} 1$ antenna array, the bandwidth is not improved to a significant level. For achieving the wider bandwidth various antenna designs are implemented. These include waveguide horns, bi-conical antennas, etc. Several broadband monopole antennas were also discussed in this regard, but the problem is that their ground planes are said to be perpendicular to the radiating elements. This makes these antennas difficult for fabrication on printed circuit boards. Recent implementations include double sided patch antennas with modifications introduced on the ground plane [18]. To be more precise, the partial ground behaves as an element for matching the impedance that shows significant effect on the impedance bandwidth of the radiating patch antenna.

Therefore, the use of partial ground is employed to improve the bandwidth capabilities for the dual trapezoidal slotted microstrip antenna array. The antenna array structure is given in the figure 10 below. Necessary changes are made in the ground plane and cut along the symmetry of the slotted patch antenna array. The dimensions are $50 \mathrm{~mm}$ along the width and $45 \mathrm{~mm}$ along the length. These values are considered by initially choosing the entire width and length of the ground plane and thereby decreasing the dimensions (W $\mathrm{x}$ L) in $1 \mathrm{~mm}$ for each instance. The dimensions of the ground plane greatly influenced the S11 parameters of the proposed antenna. Increase or decrease in the values of the width and length showed its influence on the $\mathrm{S}_{11}$ parameters. Therefore, the optimum value was taken to be $50 \mathrm{~mm} \times 45 \mathrm{~mm}$ (W $\times \mathrm{L}$ ) as they showed good reflection coefficient value. The entire scenario showed improvements in the bandwidth of the dual trapezoidal slotted patch antenna array.

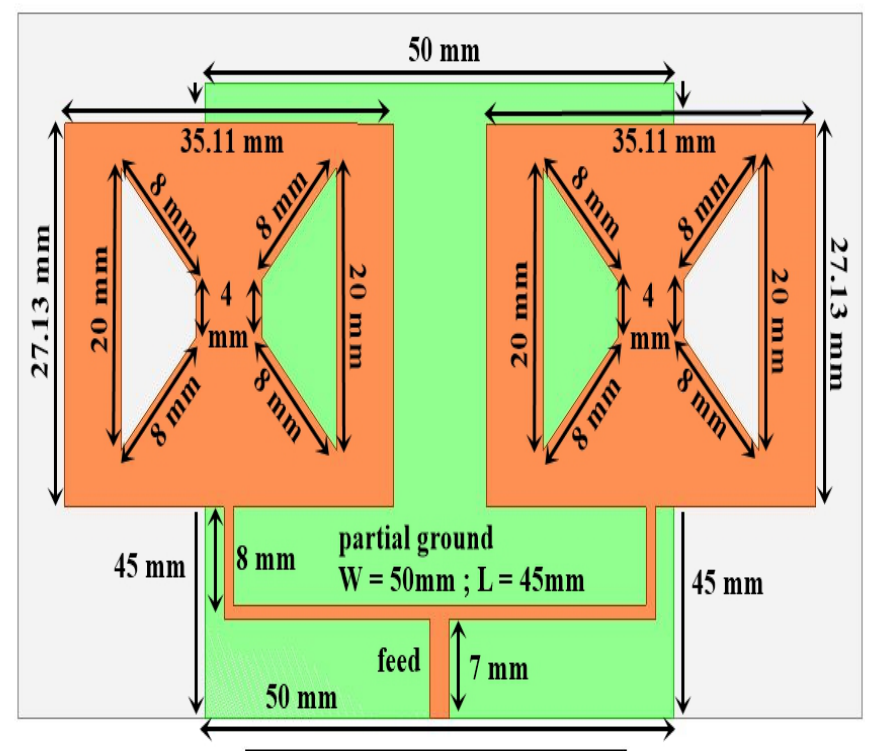

Figure 10 Dual Trapezoidal Slotted Microstrip Antenna Array with Partial Ground

\section{Findings from the Proposed Antenna with Partial Ground}

The simulations are carried out and firstly the S11 is calculated. It is found to be $-22.5779 \mathrm{~dB}$ with centre frequency $2.4020 \mathrm{GHz}$. The return loss RL which is said to be equal to $-\mathrm{S} 11$ (scattering parameter) was above $10 \mathrm{~dB}$ $(\mathrm{RL}>10 \mathrm{~dB})$ in the required frequency range from 2.30 $\mathrm{GHz}$ to $2.6 \mathrm{GHz}$. The bandwidth is measured to be $0.3 \mathrm{GHz}$ $(300 \mathrm{MHz}$ ) with the frequency range of $2.30 \mathrm{GHz}$ to 2.6 $\mathrm{GHz}$. The S11 plot is given in the figure 11 as follows.

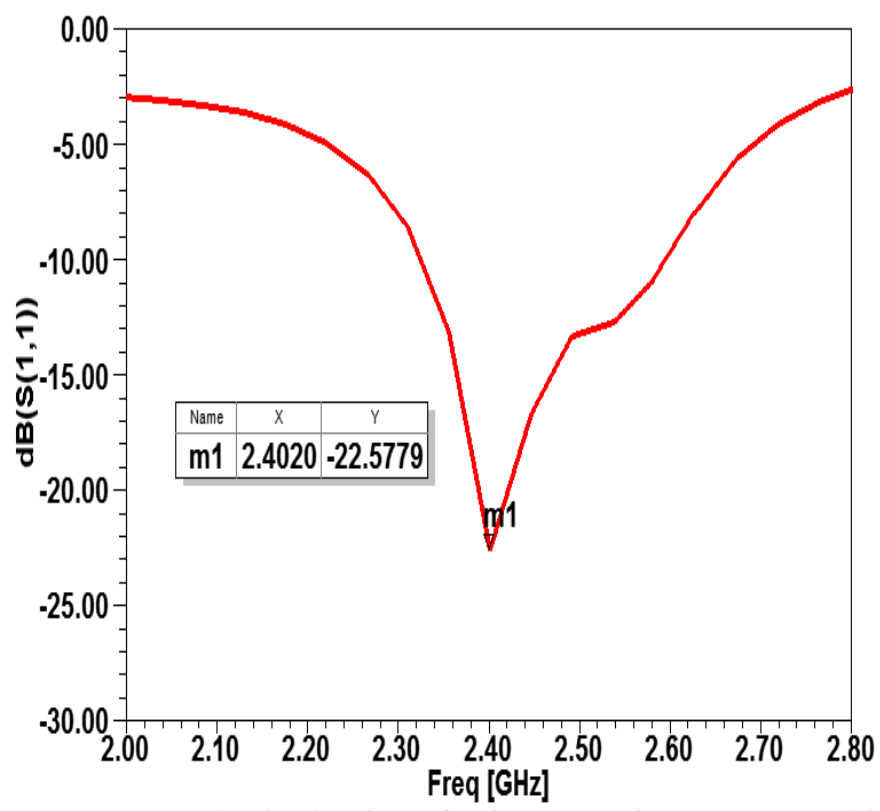

Figure 11 The simulated S11 for the proposed antenna array with partial ground 
The VSWR is plotted and is found out to be 1.1606 with centre frequency $2.4020 \mathrm{GHz}$. Reflection coefficient when considering the proposed antenna is found out to be 0.07 (0.04 in case of antenna with slots). The reflected power is calculated to be $0.5 \%(0.1 \%$ in case of antenna with slots $)$ and the mismatch loss is $0.02 \mathrm{~dB}(0.01 \mathrm{~dB}$ in case of antenna with slots). The gain was calculated and is found to be $7.0875 \mathrm{~dB}$. It is to be noted that, the proposed antenna with partial ground observed significant improvement in the bandwidth while maintaining the gain to the maximum extent possible. These are given bellow as figure 12 and figure 13

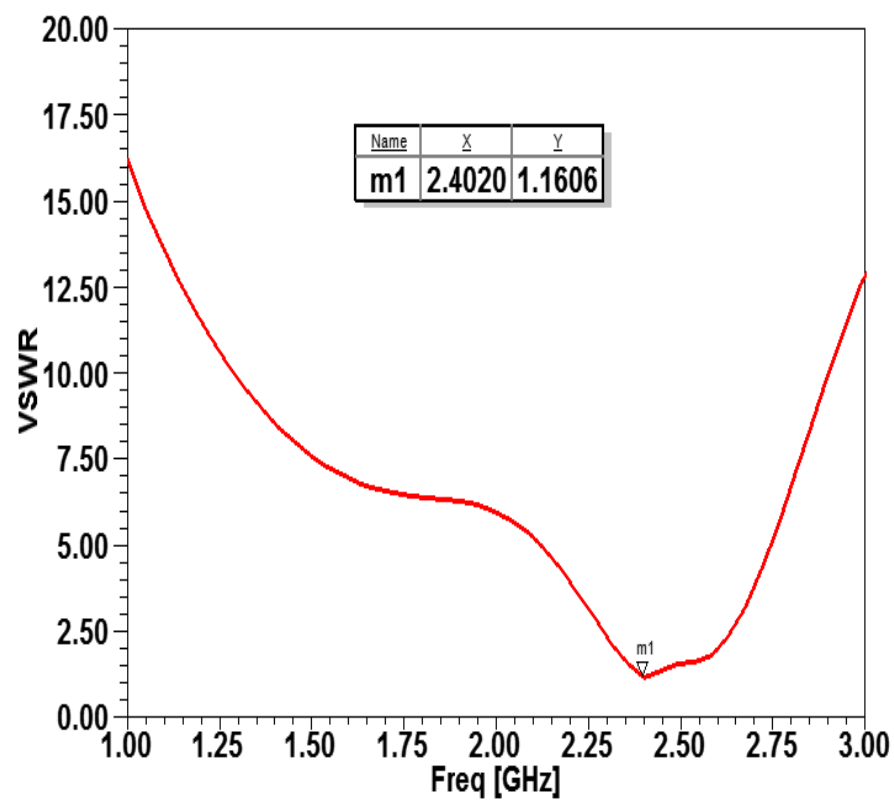

Figure 12 The VSWR plot for the proposed antenna array with partial ground

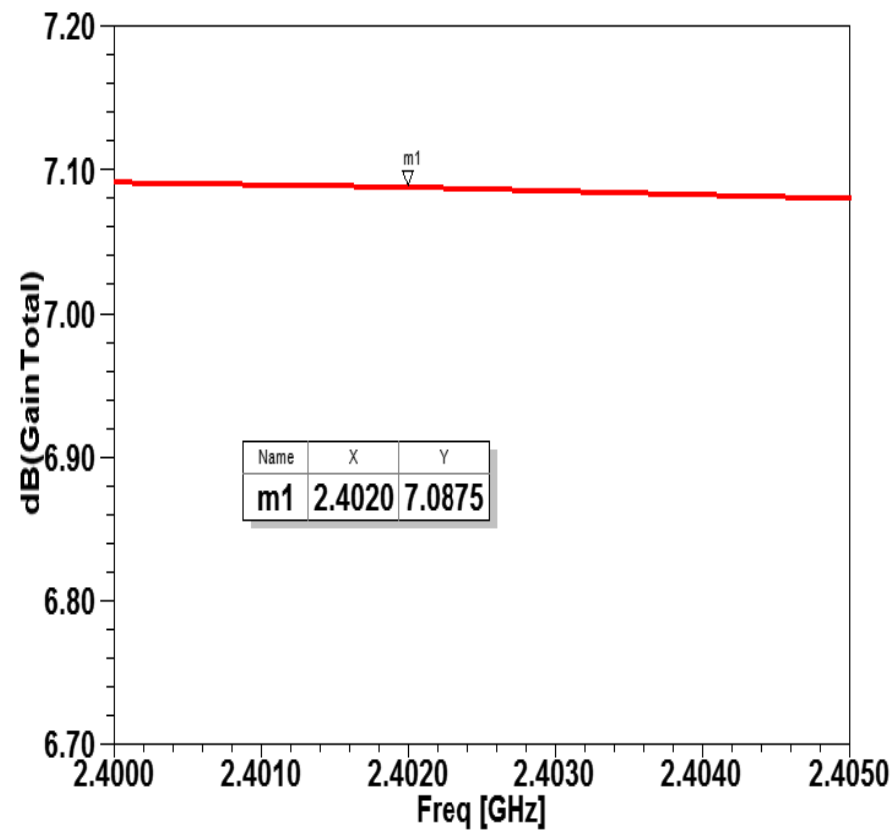

Figure 13 The 2D gain plot for the proposed antenna array with partial ground
The comparisons are carried out between the conventional 2 $\mathrm{X} 1$ array, dual trapezoidal slotted array and the dual trapezoidal slotted array with partial ground with respect to simulated S11 and gain. It is given in the figure 14 and figure 15 below.

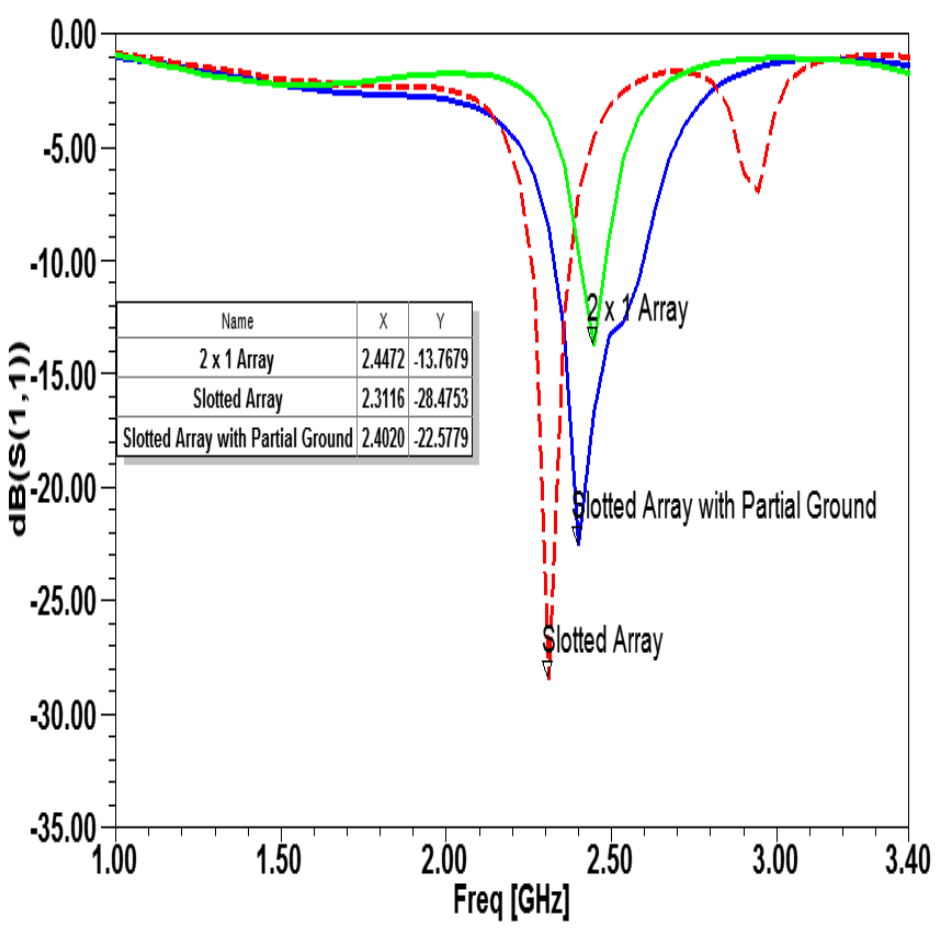

Figure 14 Simulated S11 comparison plot for the considered Antenna Array structures

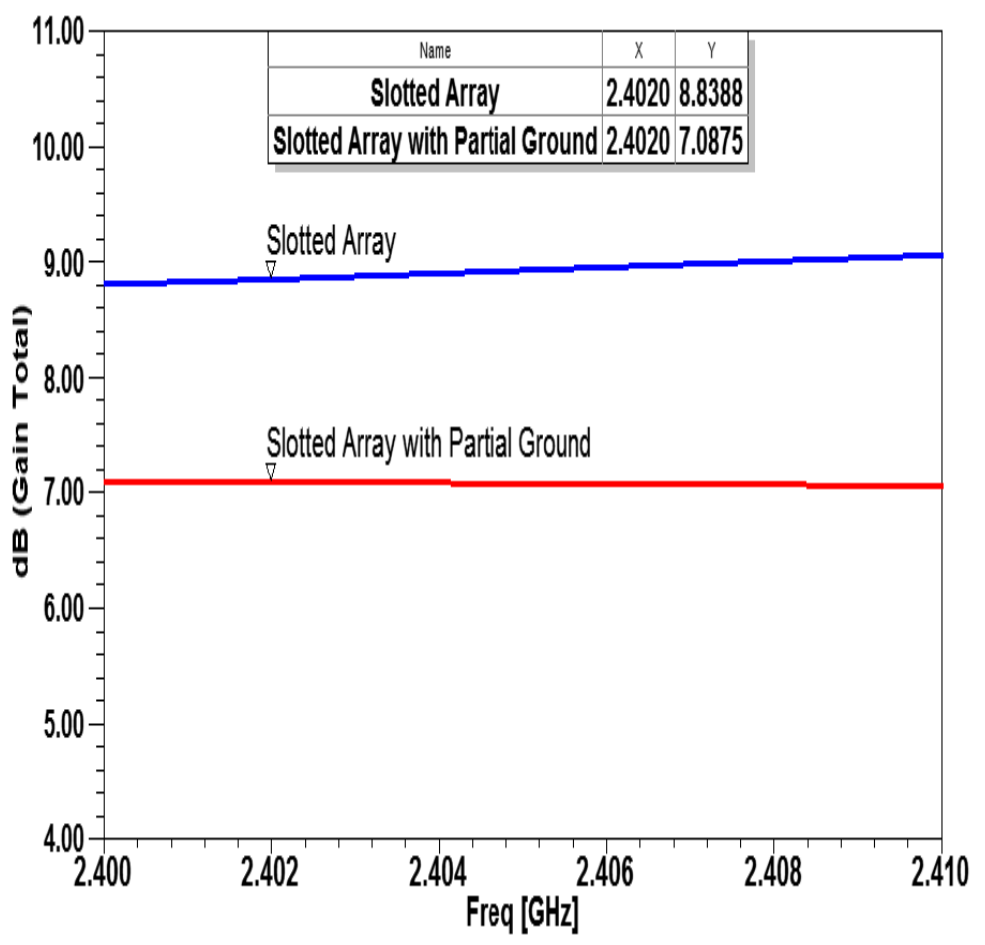

Figure 15 The 2D gain comparison plot for slotted array and slotted array with partial ground 
Table 1 Comparison of Antenna parameters for the antenna structures considered

\begin{tabular}{cccc}
\hline $\begin{array}{c}\text { Antenna } \\
\text { Parameters }\end{array}$ & $\begin{array}{c}\text { 2 X 1 Microstrip } \\
\text { Antenna Array }\end{array}$ & $\begin{array}{c}\text { Dual Trapezoidal Slot } \\
\text { Antenna Array }\end{array}$ & $\begin{array}{c}\text { Dual Trapezoidal Slot Antenna } \\
\text { Array with Partial Ground }\end{array}$ \\
\hline $\begin{array}{c}\text { Frequency Range } \\
\text { (below 10 dB) }\end{array}$ & $2.4065 \mathrm{GHz}$ to & $2.25 \mathrm{GHz}$ to $2.38 \mathrm{GHz}$ & $2.30 \mathrm{GHz}$ to $2.6 \mathrm{GHz}$ \\
Bandwidth & $2.4822 \mathrm{GHz}$ & & \\
Centre Frequency & $0.0757 \mathrm{GHz}$ & $0.1244 \mathrm{GHz}$ & $0.300 \mathrm{GHz}$ \\
Simulated S11 (dB) & $2.44 \mathrm{GHz}$ & $2.3116 \mathrm{GHz}$ & $2.4020 \mathrm{GHz}$ \\
Gain (in dB) & $-13.7679 \mathrm{~dB}$ & $-28.48 \mathrm{~dB}$ & $-22.5779 \mathrm{~dB}$ \\
VSWR & $3.8 \mathrm{~dB}$ & $7.83 \mathrm{~dB}$ & $7.0875 \mathrm{~dB}$ \\
\hline
\end{tabular}

The fabrication is done for the proposed dual trapezoidal slotted microstrip patch antenna with partial ground. The fabricated prototype is given in the figure 16 and figure 17. The fabricated antenna with partial ground is then tested and the measured results are carried out with network analyser. These are depicted in figure 18 and figure 19 below.

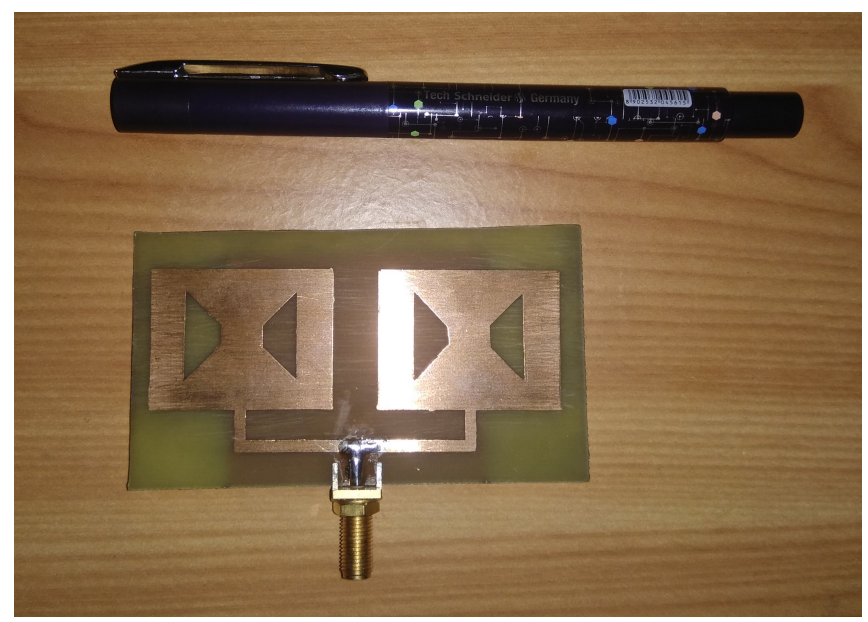

Figure 16 The Fabricated prototype of the proposed antenna; front view

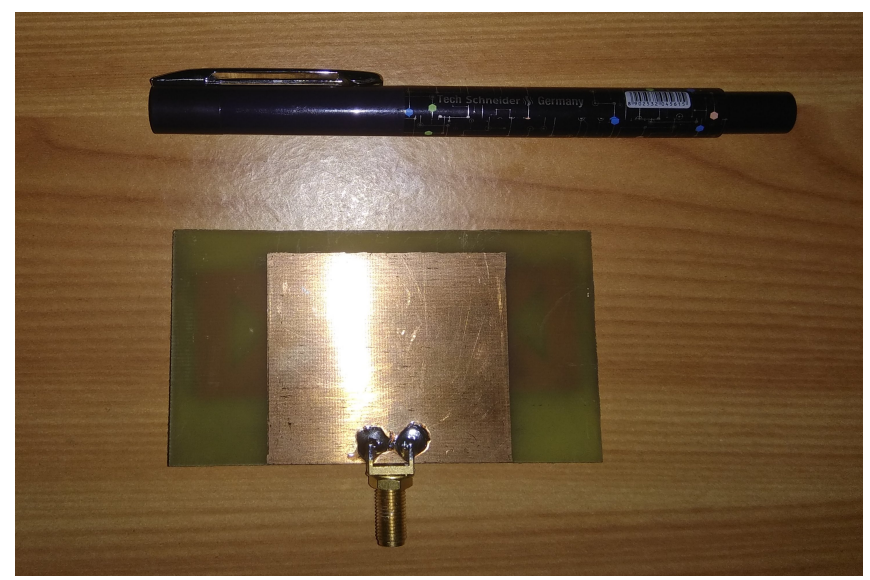

Figure 17 The Fabricated prototype of the proposed antenna; back view

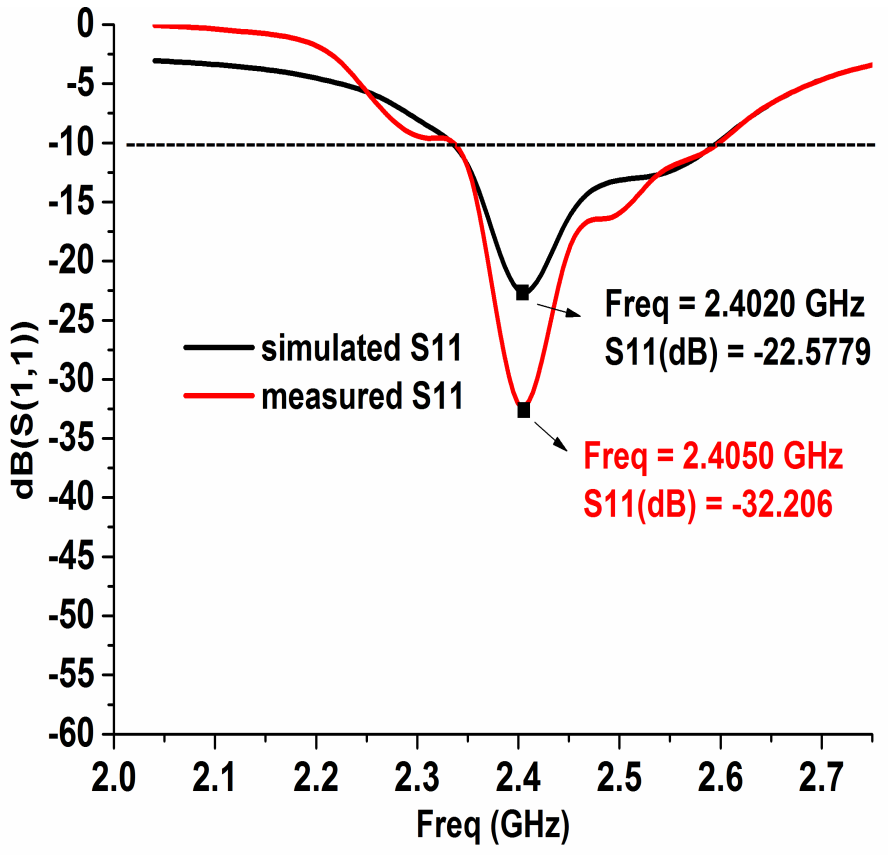

Figure 18 The S11 plot for the fabricated prototype

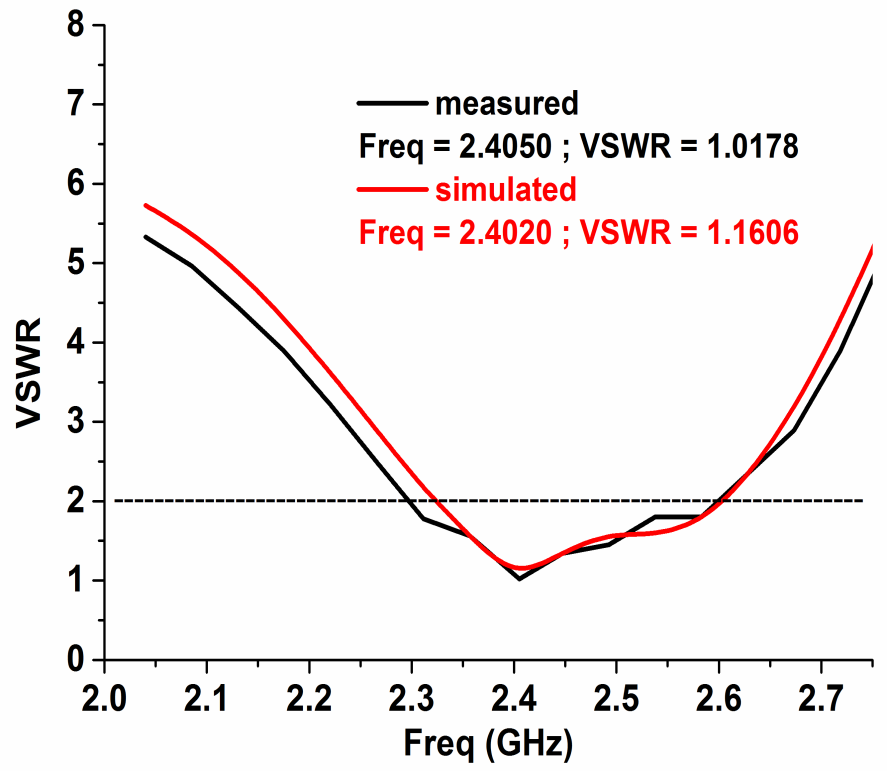

Figure 19 The VSWR plot for the fabricated prototype 
The simulated S11 was calculated to be $-22.5779 \mathrm{~dB}$ in the band range of $2.3 \mathrm{GHz}$ to $2.6 \mathrm{GHz}$ with the centre frequency 2.4020 $\mathrm{GHz}$. The measured $\mathrm{S} 11$ was found out to be $-32.206 \mathrm{~dB}$ in the band range of $2.3 \mathrm{GHz}$ to $2.6 \mathrm{GHz}$ with the centre frequency $2.4050 \mathrm{GHz}$. The Simulated VSWR was calculated to be 1.1606 (less than 2) and the measured VSWR was found out to be 1.0178 (less than 2). Therefore, the fabricated prototype is successfully tested and the measured results exhibited good agreement with the simulated results

\section{Conclusion}

For the conventional $2 \times 1$ antenna array the gain was of "3.8 dB" and bandwidth was very low of " $0.0757 \mathrm{GHz}$ ". To improve the gain of the given antenna array, dual trapezoidal slots were introduced into the patch. This made a significant improvement in the gain. The gain achieved was around "7.83 dB", and improvement is seen in bandwidth with "0.1244" GHz. Therefore, to further enhance the bandwidth of the antenna array, partial ground is considered. This further more improved the bandwidth and fractional decrease in the gain is seen. The dual trapezoidal slot antenna array with partial ground exhibited a gain of "7.0875 dB" bandwidth of " $0.300 \mathrm{GHz}$ ".

It is to be noted that the trapezoidal slots made significant increase in the gain of the microstrip antenna array and on the other hand the partial ground structure improved the bandwidth of the microstrip antenna array while preserving the gain to the maximum possible extent. Therefore, the dual trapezoidal slot microstrip antenna array with partial ground structure is found to be work in the range of 2.3 $\mathrm{GHz}$ to $2.6 \mathrm{GHz}$ with good bandwidth and gain. This frequency of operation covers the WiMax application with ranges $(2.3 \mathrm{GHz}$ to $2.4 \mathrm{GHz})$ and $(2.496 \mathrm{GHz}$ to 2.690 $\mathrm{GHz})$.

\section{REFERENCES}

[1]. Ge, Y., Esselle, K.P. and Bird, T.S., 2004. E-shaped patch antennas for high-speed wireless networks. IEEE Transactions on Antennas and Propagation, 52(12), pp.3213-3219.

[2]. Sun, L., He, M., Hu, J., Zhu, Y. and Chen, H., 2015. A butterfly-shaped wideband microstrip patch antenna for wireless communication. International Journal of Antennas and Propagation, 2015.

[3]. Huynh, T. and Lee, K.F., 1995. Single-layer single-patch wideband microstrip antenna. Electronics letters, 31(16), pp.1310-1312.

[4]. Sanad, M., 1995, June. Double C-patch antennas having different aperture shapes. In Antennas and Propagation Society International Symposium, 1995. AP-S. Digest (Vol. 4, pp. 2116-2119). IEEE.

[5]. Mekki, A.S., Hamidon, M.N., Ismail, A. and Alhawari, A.R., 2015. Gain enhancement of a microstrip patch antenna using a reflecting layer. International Journal of Antennas and Propagation, 2015.

[6]. Majid, H.A., Abd Rahim, M.K. and Masri, T., 2009. Microstrip antenna's gain enhancement using left-handed metamaterial structure. Progress In Electromagnetics Research M, 8, pp.235-247.
[7]. Yildirim, B. and Cetiner, B.A., 2008. Enhanced gain patch antenna with a rectangular loop shaped parasitic radiator. IEEE antennas and wireless propagation letters, 7, pp.229-232.

[8]. Yeap, S.B. and Chen, Z.N., 2010. Microstrip patch antennas with enhanced gain by partial substrate removal. IEEE transactions on antennas and propagation, 58(9), pp.28112816.

[9]. Mandal, K. and Sarkar, P.P., 2013. High gain wide-band Ushaped patch antennas with modified ground planes. IEEE transactions on antennas and propagation, 61(4), pp.22792282.

[10]. Raviteja, G.V., 2018. Design and analysis of a novel dual trapezoidal slot-based rectangular microstrip antenna for wide area network using WiMax application. Microwave and Optical Technology Letters, 60(4), pp.1057-1060.

[11]. Chitra, R.J., Jayanthi, K. and Nagarajan, V., 2013, March. Design of microstrip slot antenna for WiMAX application. In Automation, Computing, Communication, Control and Compressed Sensing (iMac4s), 2013 International MultiConference on (pp. 645-649). IEEE.

[12]. Raviteja, G.V., An X-Band based 2 X 1 Microstrip Antenna Array with Combined H and Dual U Slot Design Operating at $11 \mathrm{GHz}$ Frequency. Communications, 7, pp.15-20.

[13]. Midasala, V. and Siddaiah, P., 2016. Microstrip Patch Antenna Array Design to Improve Better Gains. Procedia Computer Science, 85, pp.401-409.

[14]. Srivastava, S., Singh, V.K., Singh, A.K. and Ali, Z., 2013. Duo triangle shaped microstrip patch antenna analysis for WiMAX lower band application. Procedia Technology, 10, pp.554-563.

[15]. Marzudi, W.N.N.W., Abidin, Z.Z., Dahlan, S.H., Ramli, K.N., Majid, H.A. and Kamarudin, M.R., 2015, December. Rectangular patch with partial ground wearable antenna for 2.4 $\mathrm{GHz}$ applications. In RF and Microwave Conference (RFM), 2015 IEEE International (pp. 104-109). IEEE.

[16]. Ariff, M.H., Ismarani, I. and Shamsuddin, N., 2015, August. Microstrip antenna based on rectangular patch with arms and partial ground plane for UHF RFID readers. In Control and System Graduate Research Colloquium (ICSGRC), 2015 IEEE 6th (pp. 61-65). IEEE.

[17]. Khaleel, A.D., Mansor, M.F., Misran, N. and Islam, M.T., 2016, December. Partial ground dielectric resonator antenna for LTE Femtocell base stations. In Applied Electromagnetics (APACE), 2016 IEEE Asia-Pacific Conference on (pp. 315318). IEEE.

[18]. Koohestani, M., Moghadasi, M.N. and Virdee, B.S., 2011. Miniature microstrip-fed ultra-wideband printed monopole antenna with a partial ground plane structure. IET microwaves, antennas \& propagation, 5(14), pp.1683-1689. 